\title{
Stress assignment in Hittite and Proto-Indo-European
}

\author{
Anthony D. Yates*
}

\begin{abstract}
This paper develops a new optimality-theoretic analysis of lexical accent in Hittite (Anatolian, Indo-European). I demonstrate that Hittite synchronic stress assignment is consistent with Kiparsky and Halle's (1977) BASIC ACCENTUATION PRINCIPLE, which assigns primary stress to the leftmost morpheme lexically specified for prosodic prominence or else to the left edge of a prosodic word. The Hittite evidence is thus shown to converge with Kiparsky and Halle's reconstruction of this principle for the common ancestor of the non-Anatolian Indo-European languages (i.e. ProtoNuclear-Indo-European), and in view of this agreement, argued to be reconstructible for Proto-Indo-European itself.
\end{abstract}

Keywords: Proto-Indo-European, Hittite, phonological change, historical linguistics, lexical accent, stress.

1. Introduction: The stress systems of Proto-Indo-European (PIE) and its oldest daughter languages have long been a source of interest and controversy in Indo-European and theoretical linguistics. Still much disputed are, on the one hand, the surface stress patterns that should be reconstructed for the proto-language and, on the other, how these reconstructed patterns should be analyzed. The primary aim of this paper is to bring to bear on these questions largely neglected evidence from the Anatolian languages - in particular, Hittite, the major representative of this extinct branch. Specifically, I argue that Hittite stress assignment provides crucial support for the hypothesis advanced by Kiparsky and Halle (1977), whose synchronic analyses of word stress in Lithuanian, Russian, Ancient Greek, and Vedic Sanskrit lead them to reconstruct for PIE a LEXICAL ACCENT system (e.g. Revithiadou 1999; Alderete 2001) in which stress is determined by the Basic ACCEntuAtion PRinciple (BAP) stated in (1) (cf. Kiparsky 2010):

\section{Basic ACCEntuation PRinciple (BAP):}

If a word has more than one accented syllable, the leftmost of these receives word stress. If a word has no accented syllable, the leftmost syllable receives word stress.

Although not treated by Kiparsky and Halle, the Anatolian languages in fact have special importance in assessing this reconstruction due to their unique position within the IE family. It is now the consensus view that Anatolian was first to diverge from the other language branches of the IE family, which share a proximate common ancestor, termed Proto-Nuclear-Indo-European (PNIE); this relationship is represented in the (schematic) family tree in (2): ${ }^{1}$

\footnotetext{
*I would like to acknowledge a debt of gratitude to David Goldstein, Dieter Gunkel, Jesse Lundquist, Craig Melchert, Ryan Sandell, and Sam Zukoff for critical comments and discussion, as well as to audiences at the UCLA Phonology Seminar and M.I.T Phonology Circle. Naturally, any remaining errors are my own. Author: Anthony D. Yates, University of California, Los Angeles (adyates@ucla.edu).

${ }^{1}$ The traditional label for this once controversial split is the "Indo-Hittite hypothesis" (Sturtevant 1929, 1933). For a recent assessment of the relationship between Anatolian and PNIE - elsewhere referred to equivalently as "Core PIE" or "Restindogermanisch" — see (e.g.) Melchert (to appear).
} 


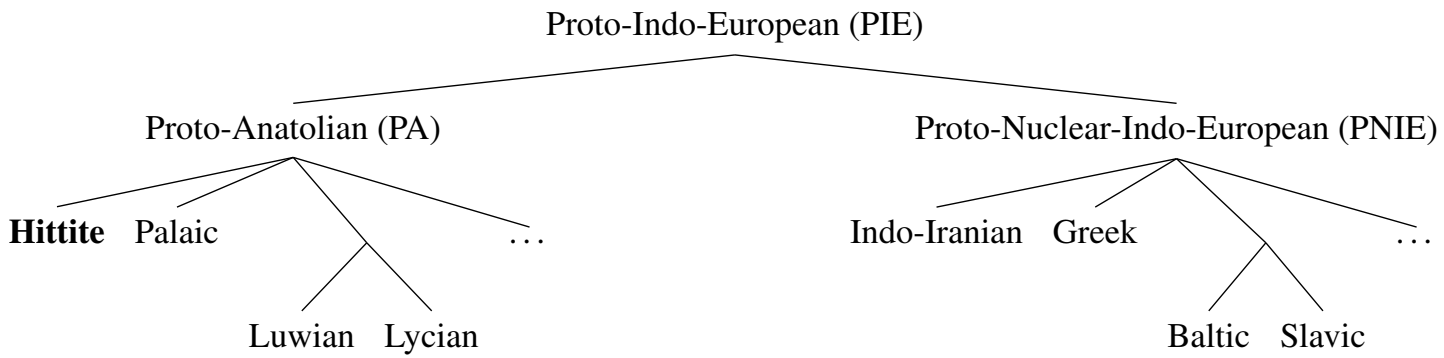

This relationship between Anatolian and the other IE languages logically admits the possibility that, even if Kiparsky and Halle's reconstruction of the BAP for PNIE is correct, stress in PIE itself operated according to different principles, a possibility that is implicit in traditional "paradigmatic" approaches to PIE stress as presented in standard IE handbooks (to be discussed in section 4.3 below). However, it will be demonstrated in section 3 that stress in Hittite - and very likely, Proto-Anatolian (PA) - is consistent with the BAP, which can therefore be securely reconstructed for PIE itself.

The remainder of this paper is structured as follows. Section 2 provides some background on the Anatolian languages and a descriptive overview of the Hittite stress system, including the primary data to be considered. A new synchronic analysis of this data is advanced in section 3. where I develop an optimality-theoretic implementation of the BAP, and show that correctly generates attested patterns of word stress in Hittite verbal inflection. Finally, section 4 turns to diachrony: Anatolian is shown to support the reconstruction of the BAP for PIE, and the historical implications of this reconstruction for stress in PIE and its daughter language are assessed.

2. An overview of Hittite stress: This section establishes the foundation for an analysis of Hittite stress. After briefly introducing the Hittite language in section 2.1, I proceed in section 2.2 to set out the philological and phonological assumptions underlying the analysis to be developed. Section 2.3 presents an overview of the Hittite stress system, situating it in Indo-European and cross-linguistic perspective. The primary data to be examined is then set out in section 2.4.

2.1. HistoricAl BACKGROUnd: The Anatolian languages are attested in the 1st and 2nd millennium BCE primarily in what is now central Turkey and northern Syria. The earliest and by far the most extensive records are of Hittite, which is attested continuously from the 16th-13th centuries BCE in multi-genre administrative texts, the majority on clay tablets from the Hittite capital of Hattuša near modern Boğazkale. ${ }^{2}$ Thanks to these textual records — in fact, the oldest of any IE language - Hittite is also the best understood member of the Anatolian languages, and thus the most importance source of information for the reconstruction of stress in PA.

2.2. PhONOLOGICAL \& ORTHOGRAPHIC PRELIMINARIES: Extracting prosodic information from Hittite texts is a difficult task, vexed by philological problems and (in some cases) controversial questions of phonological interpretation; I therefore begin by laying out the assumptions that

\footnotetext{
${ }^{2}$ The Hittite language is chronologically stratified into three stages: Old Hittite (OH), Middle Hittite (MH), and New Hittite (NH) (see Hoffner and Melchert 2008:xvii); though very problematic to quantify, a reasonable approximation for the size of the corpus is $\sim 136,000$ words (cf. Kloekhorst 2008:222), the majority of which occur in NH texts.
} 
guide the analysis developed below. ${ }^{3}$

It is assumed here that Hittite has the phonemic inventory in (3), with contrastive length in most consonants and the low/high vowels:

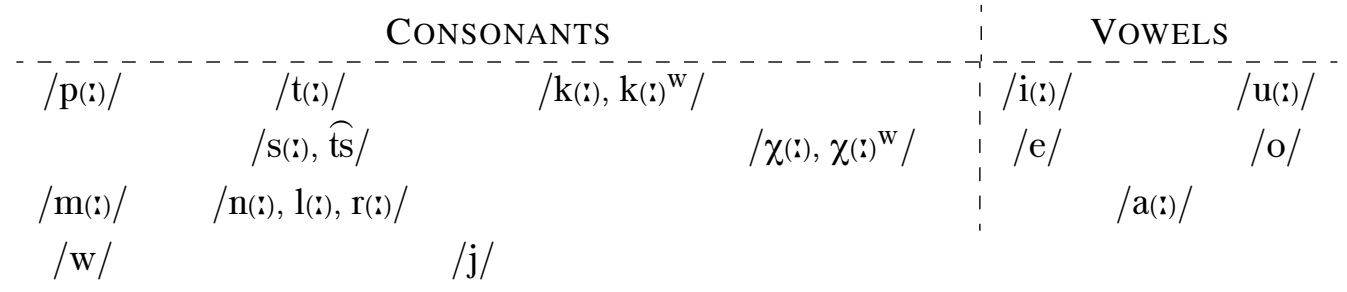

Hittite is written in a cuneiform mixed syllabic-logographic script. Syllabic signs may have the value $C V, V C, V$, or (less commonly) $C V C$. Word stress is not directly represented in this orthographic system; however, Hittite scribes did encode the effects of word stress on vowel quantity and quality, which make it possible to indirectly diagnose its position. The first and most important of these diagnostics is so-called PLENE WRITING, the optional repetition of an identical $V$ sign in the spelling of vowels or diphthongs (Kimball 1999), which is now generally agreed to mark vowel length (as already pointed by Hrozný 1917:xii). Vowel length in Hittite closely coincides with stress due to a combination of historical and synchronic processes that shorten unstressed long vowels and lengthen most stressed short vowels.

The other major diagnostic for Hittite word stress is vowel reduction. In addition to the shortening of unstressed long vowels just noted, there is also a strong tendency for non-peripheral vowels $(/ \mathrm{e}, \mathrm{o} / \mathrm{)}$ to reduce to peripheral vowels in unstressed syllables $([\mathrm{i}, \mathrm{u}, \mathrm{a}])$, as well as a limited pattern of vowel deletion in pre-tonic syllables.

These orthographic practices allow for two generalizations concerning Hittite word stress: (i) if a vowel is written plene, then it is long/stressed; and (ii) reduced vowels are unstressed. ${ }^{4}$ These generalizations provide the basis for phonological interpretation of the primary data in section 2.4, and consequently, the analysis advanced in section 3 below.

2.3. Hittite stress in IE And typological Perspective: The Hittite prosodic system broadly shares at least three features with other ancient IE languages - in particular, the oldest representatives of the Indic (Vedic Sanskrit), Greek (Homeric Greek), and Balto-Slavic language branches, which are generally agreed to preserve the inherited stress system most faithfully, and converge in the reconstruction of a PNIE system with these properties. One such shared feature is CULMINATIVITY (e.g. Hyman 2006): each Hittite word had a single most prosodically prominent syllable (i.e. stress), whose vowel is optionally written plene. Culminativity explains why — with just a few, mostly principled exceptions (cf. n. 4) - no more than one vowel per word shows plene writing.

Another feature common to these languages is FREE STRESS. In Hittite, stress can occur on any syllable of a prosodic word, with no evident phonological restrictions (e.g. an edge-oriented

\footnotetext{
${ }^{3}$ For a fuller defense of the views adopted in this section, see Melchert (1994:133, 146-7) and Yates (2015b), as well as Kimball (2015) for additional arguments against Kloekhorst's (2014) alternative views on vowel length.

${ }^{4}$ Generalization (i) is complicated somewhat by a relatively small number of cases in which more than one vowel in a word is spelled plene. However, this phenomenon is almost exclusively confined to complex derivation (see Yates 2015b), and exceptions within the inflectional paradigms of radical formations like those considered in section 3 are rare enough that they can be attributed to non-linguistic factors such as scribal error.
} 
window) on its surface distribution. Both free stress and culminativity can be observed in (4): ${ }^{5}$

\begin{tabular}{|c|c|c|c|}
\hline $1 \mathrm{ST} \sigma$ & $2 \mathrm{ND} \sigma$ & $3 \mathrm{RD} \sigma$ & 4TH $\sigma+$ \\
\hline $\bar{e}$ šhar 'blood' & išh̆ā̌s 'master' & alwanzātar 'sorcery' & kukupalätar 'deception' \\
\hline [éss $\chi: a r]$ & 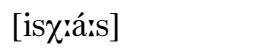 & [alwantsá:tar] & [kukupalá:tar] \\
\hline $\begin{array}{l}\text { pēdan 'place' } \\
\text { [pé:tan] }\end{array}$ & $\begin{array}{l}\text { aššūl 'well-being' } \\
\text { [as:ú:l] }\end{array}$ & 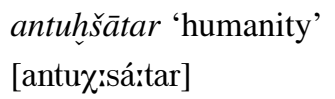 & $\begin{array}{l}\text { annitalwātar 'capacity to be } \\
\text { [an:italwá:tar] a mother' }\end{array}$ \\
\hline $\begin{array}{l}\text { nēpišaš ‘heaven’ (Gen.s.) } \\
\text { [né:pisas] }\end{array}$ & $\begin{array}{l}\text { takšūl 'peace' } \\
\text { [taksú:l] }\end{array}$ & $\begin{array}{l}\text { išhiūl ‘binding; treaty’ } \\
\text { [iš:ijú:l] }\end{array}$ & $\begin{array}{l}\text { išhanattarātar 'marriage bond' } \\
\text { [is } \chi \text { :anat:ará:tar] }\end{array}$ \\
\hline
\end{tabular}

The examples in (4) further show that Hittite stress cannot be predicted on the basis of purely phonological factors such as metrical structure or syllable weight; rather, the fact that (e.g.) all abstract nouns containing the suffix - attar are stressed on the first vowel of the suffix, or that all nouns with the suffix $-\bar{u} l$ are stressed on this suffix, suggests that morphological constituency is the primary determinant of word stress. This morphological dependency is the defining feature of what are generally referred to as LEXICAL ACCENT systems (Revithiadou 1999; Alderete 2001), which are also found in non-IE languages like Cupeño and Tokyo Japanese. In such systems, morphemes may be lexically specified as preferred hosts of word stress, an underlying feature standardly termed ACCENT. This lexical feature offers a natural explanation for the regularity with which morphemes like - attar and $-\bar{u} l$ are stressed: these derivational suffixes are accented (/-á:tar, $-u ́: l /)^{6}$

Lexical accent systems of this kind also have a set of morphophonological principles responsible for adjudicating between multiple accented morphemes competing for primary stress, as well as assigning "default" stress when a word contains no accented morphemes. Analyzing such systems thus requires determining both the accentual properties of each morpheme, as well as the language-specific morphophonological principles relevant to stress assignment, which may be understood as set of rules or - as here — ranked constraints; this task will be taken up for Hittite in section 3 below.

2.4. Mobile stress in Hittite And IE verbal inflection: The primary analytic goal of this paper is to provide a synchronic account of Hittite MOBILE STRESS, viz. alternations in word stress within a word's inflectional paradigm. Mobile stress - or traces thereof — is evident in virtually all ancient Indo-European languages, and remains productive in the Hittite verbal system. $^{7}$ In particular, stress mobility is regularly observed in RADICAL verbs, a class formed by adding inflectional suffixes directly to a verbal root.

From a synchronic perspective, radical verbs in Hittite belong arbitrarily to one of two conjugational classes, the $m i-$ or the $h i-$ conjugation, which have phonologically distinctive fusional (person/number/tense) inflectional endings in singular forms. Both classes are characterized by

\footnotetext{
${ }^{5}$ All Hittite examples in this paper are presented both in so-called "broad transcription" (see Hoffner and Melchert 2008:11-2), where plene writing is marked by a macron, and in an approximate phonetic transcription, where stress is marked with an acute accent.

${ }^{6}$ Alternatively, derivational suffixes may be stressed because they are morphological heads (cf. Revithiadou 1999); for arguments that stress in Ancient Greek and Vedic Sanskrit is head-dependent, see Sandell (2015:161-214).

${ }^{7}$ Evidence for mobile stress in the Hittite nominal system is extremely limited, and almost strictly confined to the most archaic stratum of the lexicon, e.g. tēkan [té:kan] 'earth' (NOM/ACC.SG.) vs. taknāšs [takn-á:s] (GEN.sG.). It remains unclear whether such alternations were synchronically generated at any attested stage of the language.
} 
mobile stress, exhibiting alternations between stress on the verbal root in the singular and the first syllable of inflectional endings in the plural, e.g. (5):

a. Hitt. mobile $m i$-verbs:

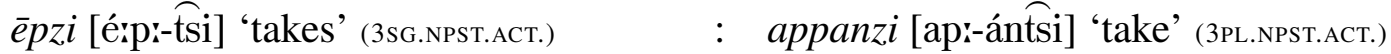

$$
\begin{aligned}
& \text { Hitt. } \check{s} e \bar{s} z i \text { [sérs-ți] 'sleeps' (3sg.nPst.Aст.) : } \quad \check{s} a s ̌ a n z i \text { [sas-ántsi] 'sleep' (3PL.nPst.Aст.) }
\end{aligned}
$$

b. Hitt. mobile hi-verbs:

$$
\begin{aligned}
& d \bar{a} i \text { [tá:-j] 'takes' (3sg.nPst.Aст.) : dattēni [ta-tré:ni] 'you take' (2PL.NPST.Aст.) } \\
& k \bar{a} n k i \text { [ká:nk:-i] 'hangs' (3sg.NPST.Aст.) : kankanzi [kank:-ántsi] 'hang' (3PL.NPST.Aст.) }
\end{aligned}
$$

For all four verbs in (5), stress on the verbal root in the 3rd person singular is confirmed by plene writing of the root syllable. A shift of stress onto plural inflectional endings is observed in datteni [ta-t:é:ni], again as shown by plene writing, while the short/reduced vowel ([a]) of the root in the other verbs is indicative of the same shift.

Yet while Hittite radical verbs overwhelmingly exhibit mobile stress, this dominant pattern nevertheless contrasts with FIXED root stress in a small set of radical verbs. This class includes at least wek- 'demand', a mi-verb, and two hi-verbs, arr- 'wash', and anš- 'wipe'; all three are given in (6), where significantly, the plural forms show evidence of root stress - for wek-, consistent root $e$-vocalism, and for arr- and anš-, plene writing of the root vowel $(\bar{a})$ :

$$
\begin{aligned}
& w \bar{e} k z i \text { 'demands' [wé:k-ți] (3sg.npst.Act.) : wekanzi [wé:k-antsi] 'demand' (3PL.nPST.Aст.) } \\
& \text { ārri 'washes' [árr:-i] (3sg.nPst.Act.) } \quad: \text { a }
\end{aligned}
$$

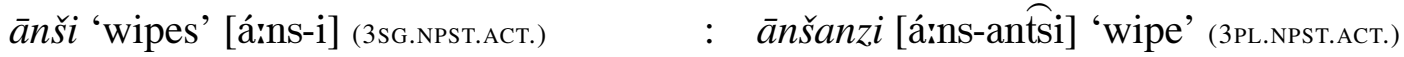

The IE prehistory of these (non-)alternations has long been established. The mobile stress pattern of Hittite radical $m i$-verbs is matched exactly by Vedic Sanskrit radical present stem formations (i.e. Class II, in terms of the Sanskrit grammarians), which in some cases can even be observed in cognate lexical items - compare (e.g.) Ved. sás-ti : sas-ánti 'sleep(s)' with Hitt. šešin (5a). Similarly, a plausible diachronic explanation exists for the exceptional fixed stress pattern of Hitt. wek-, which although synchronically simplex, historically continues a derived "Narten formation" (Melchert 2014). However, as will become clear especially in sections 3.4-3.5 below, these Hittite verbal roots show systematic stress differences across productive morphological categories, a clear synchronic split that can only be generated by the grammar of Hittite speakers (not just their PIE ancestors). A synchronic explanation for these differences is thus developed in the next section.

3. A new analysis of Hittite stress: This section develops an optimality-theoretic analysis of synchronic Hittite stress assignment. The three major components of this analysis, including the constraint inventory, is laid out in section 3.1. These are applied to derive mobile and fixed stress patterns in Hittite verbal inflection in sections 3.2 and 3.3 respectively. More complex verbal formations are analyzed in section 3.4, where they are shown to fall out from the left-edge preference dictated by the BAP, while section 3.5 provides explicit arguments for the synchronic status of this principle in Hittite. 
3.1. COMPONENTS OF THE ANALYSIS: The synchronic contrast between mobile and fixed root stress in Hittite radical verbs falls out from three basic assumptions. The first of these is an underlying accentual contrast in verbal inflectional endings: the singular (non-past) endings are unaccented, the plural endings accented, i.e. (7).

$$
\text { mi-CONJUGATION hi-CONJUGATION }
$$

\begin{tabular}{|c|c|c|c|c|c|c|c|c|}
\hline & \multicolumn{4}{|c|}{$m i$-CONJUGATION } & \multicolumn{4}{|c|}{$h i$ i-CONJUGATION } \\
\hline & SING & JLAR & & JRAL & SINC & ULAR & & URAL \\
\hline $1 \mathrm{ST}$ & $-m i$ & /-mi/ & - weni & /-wéni/ & $-h h i$ & /- $\chi: \mathrm{i} /$ & - weni & /-wéni/ \\
\hline $2 \mathrm{ND}$ & $-\check{s} i$ & /-si/ & -tteni & /-tréni/ & $-t t i$ & /-tri/ & $-(\check{S})$ teni & /-(s)tiéni/ \\
\hline $3 \mathrm{RD}$ & $-(z) z i$ & /-דิtsi/ & $-a n z i$ & /-ántsi/ & $-i$ & $/-\mathrm{i} /$ & $-a n z i$ & /-ántsi// \\
\hline
\end{tabular}

The second assumption is that there is a parallel accentual contrast in verbal roots. Specifically, I propose that Hittite radical verbs which show mobile stress are built to unaccented roots, while in the restricted set of verbs with fixed root stress, the verbal root is accented, i.e. (8):

\begin{tabular}{|c|c|c|}
\hline \multicolumn{2}{|c|}{ UNACCENTED } & ACCENTED \\
\hline /ep:-/ 'take' & /ka:nk:-/ 'hang' & /wék-/ 'demand' \\
\hline /ses-/ 'sleep' & /ta:-/ 'take' & /árr:-/ 'wash' \\
\hline & .. & /ázns-/ 'wipe' \\
\hline
\end{tabular}

The third and final component of the analysis is a ranking of (morpho)phonological constraints that correctly generates attested surface stress patterns (cf. 2.3 above). As will be demonstrated in sections 3.2-3.3 below, Hittite inflectional stress is consistent with the operation of Kiparsky and Halle's (1977) BAP (given in (1) above), which can be viewed as the result of an interaction between the four basic markedness and faithfulness constraints in (9):

(9) a. Align-L(Pk, $\omega)$ (Align-L): Assign one violation (*) for each syllable between a stressed syllable and the left edge of a prosodic word.

b. Culminativity (Culm): A prosodic word must have exactly one stressed syllable.

c. $\operatorname{MAX}($ Accent): A lexical accent in the input must correspond with a stressed syllable in the output.

d. DEP(Accent): A stressed syllable in the output must correspond with a lexical accent in the input.

When ranked as in (10), with CULM at the top of the grammar, and MAX dominating DEP and ALIGN-L, the left-edge oriented stress pattern dictated by the BAP emerges: the leftmost accented syllable of a prosodic word will bear word stress, or else stress defaults to its left edge. ${ }^{8}$

$$
\text { Culminativity } \gg \operatorname{MAX}(\text { Accent }) \gg \operatorname{DEP}(\text { Accent }), \operatorname{Align-L}(\mathrm{Pk}, \omega)
$$

\footnotetext{
${ }^{8}$ An additional constraint — * FLOP(ACCENT) (vel sim.) — is required to enforce faithfulness between lexical accents and their input associations (see Alderete 2001:23-5, Revithiadou 1999:53-4); candidates violating this constraint are not considered here.
} 
3.2. DeRIVING MOBILE STRESS: Applying this constraint ranking to the Hittite data introduced in 2.4, mobile stress surfaces whenever the verbal root is unaccented. For instance, /ses-/ 'sleep' exhibits root - or equivalently, leftmost — stress when it combines with (also unaccented) singular inflectional endings: ${ }^{9}$

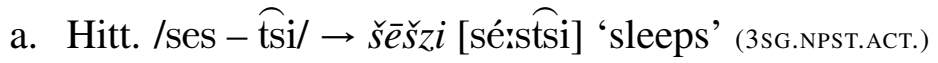

b.

\begin{tabular}{|lc||c|c|c|c|}
\hline \multicolumn{2}{|c||}{ /ses - tsi/ } & CULM & MAX(Accent) & DeP(Accent) & ALIGN-L \\
\hline \hline a. & sestsi & $* !$ & & & \\
\hline b. & séstsisi & & & $*$ & \\
\hline c. & sestsí: & & & $*$ & $* !$ \\
\hline
\end{tabular}

(11) is indicative of what occurs when a word contains no accented morphemes. In the tableau in (11b), the faithful candidate (a) is ruled out by by CULMINATIVTY, which must be satisfied by insertion of an accent. Candidate (b), where the inserted accent associates with the root syllable, is then preferred to (c), which gratuitously violates ALIGN-L. (11) thus shows "default" stress, i.e. the emergence of the general phonological preference for left-edge stress.

In plural forms of /ses-/, however, stress falls instead on the plural inflectional endings, which are accented; a representative example is given in (12), where the root is suffixed with the 3rd plural ending /-ántsi/:

a. /ses - ánți// $\rightarrow$ šašanzi [sasántsii] ‘sleep’ (3PL.NPST.ACT.)

b.

\begin{tabular}{|lc||c|c|c|c|}
\hline \multicolumn{2}{|c|}{$/$ ses - ántsi/ } & CULm & MAX(Accent) & DEP(Accent) & ALIGn-L \\
\hline \hline a. & sasantsi & $* !$ & $*$ & & \\
\hline b. & sasántsi & & & & $*$ \\
\hline c. & séssantsi & & $* !$ & $*$ & \\
\hline d. & sésántsi & $* !$ & & $*$ & $*$ \\
\hline
\end{tabular}

The tableau in (12b) shows that, when a word contains exactly one accented morpheme, the faithful candidate is optimal - in this case, (b) violates only low-ranked ALIGN-L, while candidate (c), which better satisfies ALIGN-L, is excluded because it violates higher-ranked MAX(Accent).

3.3. DERIVING FIXED STRESS: Fixed stress, in contrast, arises as a direct consequence of root accentedness. The surface stress pattern of fixed stress verbs contrast with mobile verbs in all plural forms, where the lexical accent of the root competes with the accent of the inflectional ending for primary stress. This competition is exemplified using the $m i$-verb /wék-/ 'demand' in (13): ${ }^{10}$

\footnotetext{
${ }^{9}$ Due to space constraints, I omit here a formal analysis of hi-verbs, which could be treated along the same lines.

${ }^{10}$ I assume that absence of plene writing in the 3rd plural of Hitt. wek- owes to orthographic, not phonological factors; the invariant root-final singleton velar stop $-k-([\mathrm{k}])$ - in particular, in imperfectives containing the suffix -ške(cf. Melchert 2014:255 n. 8) - is indicative of a prehistoric ${ }^{\prime} \bar{e}$ in both singular and plural paradigmatic forms (whether original or analogical), and interpret the consistent root $e$-vocalism as indicating that [é:] is maintained synchronically in Hittite (cf. Yates 2015b).
} 
a. /wék - ánți/ $\rightarrow$ wekanzi [wé:kantsi] 'they demand' (3PL.NPST.ACT.)

b.

\begin{tabular}{|lr||c|c|c:c|}
\hline \multicolumn{2}{|c|}{ /wék - ántsi/ } & CULM & MAX(Accent) & DEP(Accent) & ALIGN-L \\
\hline \hline a. & wé:kántsi & $* !$ & & & $*$ \\
\hline b. & wé:kantsi & & $*$ & & $* !$ \\
\hline c. & wakántsi & & $*$ & & \\
\hline d. & wekantsi & $* !$ & $* *$ & & \\
\hline
\end{tabular}

In the tableau in (13b), satisfying top-ranked CULIMINATIVITY necessitates deleting one accent; ALIGN-L then adjudicates between candidates (b) and (c), preferring the latter because stress is situated closer to the left-edge of the prosodic word.

3.4. CompleX InTERACTIONS $\Rightarrow$ LefTMOST WinS: The constraint ranking in (10) therefore accounts for the synchronic stress contrast between accented and unaccented roots in their basic inflectional paradigms. Yet an equally important feature of this analysis is that is capable of generalizing to more morphologically complex formations with multiple accented affixes.

One major locus for such interactions between accented morphemes is in the formation of Hittite suffixed verbal stems aspectually marked for imperfectivity. This highly productive class is formed by addition of an accented suffix /-sk:é-/ (-ške-) to a verbal root or stem immediately before person/number accentings. Because this suffix is accented, Hittite imperfectives exhibit fixed suffixal stress in combination with unaccented roots, e.g. / $\mathrm{k}^{\mathrm{w}}-/$ 'drink' in (14). ${ }^{11}$ In singular forms like (14a), stress assignment to the suffix is trivial, as it is the only accented morpheme. A more significant data point, though, is the plural in (14b), where there are two accented morphemes; in this case, the same constraint ranking correctly predicts that the leftmost affix - i.e. the imperfective suffix — will bear word stress, as evident in the tableau in (14c): ${ }^{12}$

a. $/ \mathrm{ek}^{\mathrm{w}}$ - sk:é - sil/ $\rightarrow$ akkuškēesi [ak:uskeéssi] 'you drink' (IPFv-2S.nPST.Aст.)

b. /ek ${ }^{\mathrm{w}}$ - sk:é - wéni/ $\rightarrow a k k u s ̌ k e \bar{e} w a n i$ [ak:usk:é:wani] 'we drink' (IPFV-1PL.NPST.Act.)

c.

\begin{tabular}{|c|c|c|c|c|c|}
\hline \multicolumn{2}{|c|}{ /ekw - sk:é - wéni/ } & Culm & MAX(Accent) & DEP(Accent) & ALIGN-L \\
\hline a. & ak:usk:é:wé:ni & $* !$ & & & $* * * * *$ \\
\hline b. & ak:usk:é:wani & & * & & $* *$ \\
\hline c. & a:k:usk:ewé:ni & & * & & $* * * !$ \\
\hline d. & é:kusk:ewani & & $* * !$ & * & \\
\hline
\end{tabular}

This analysis also accounts for the previously unexplained fact that imperfective stems of accented verbal roots are consistently stressed on the root just as in their basic inflectional paradigm. Instead of ignoring this commonality or ascribing it to the murky operation of analogical processes, this exact surface stress distribution is in fact predicted, i.e. (15):

${ }^{11}$ The unaccented status of this root is shown by its mobile paradigm: $\bar{e} k u z i$ [ér $\mathrm{k}^{\mathrm{W}}$-ți] 'drinks' (3SG.NPST.ACT.) : akuanzi [ak ${ }^{\mathrm{w}}$-ántsi] 'drink' (3PL.NPST.ACT.).

${ }^{12}$ The [i] and [u] vowels appearing between the root and imperfective suffix in (14-15) are epenthetic; see Kavitskaya (2001) and Yates (2014). 


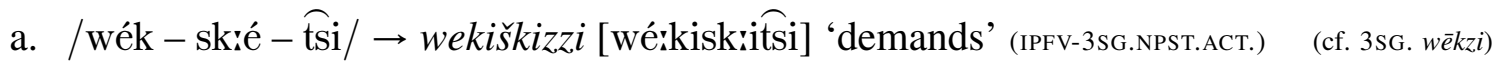

b.

\begin{tabular}{|lr||c|c|c|c|}
\hline \multicolumn{2}{|c|}{ /wék - sk:é - tsi/ } & CULM & MAX(Accent) & DEP(Accent) & AliGN-L \\
\hline \hline a. & wé:kisk:é:tsi & $* !$ & & & $* *$ \\
\hline b. & wérkisk:itsi & & $*$ & & \\
\hline c. & wakisk:é:tsi & & $*$ & $*$ \\
\hline
\end{tabular}

The same split between accented and unaccented roots that was observed in Hittite imperfectives also arises in another productive verbal category, the participle. Hittite participles, which typically express a passive-like resultant state with transitive verbs or an attained state with intransitive verbs (Hoffner and Melchert 2008:339-40), are formed by suffixing /-ánt-/ (-ant-) to a verbal root or stem prior to (nominal) inflectional endings. Just like the imperfectives, participles to unaccented verbal roots show fixed stress on the participle suffix vs. fixed stress on the root in participles to accented roots - compare (16) and (17) respectively:

a. /ep: - á:nt - s/ appānza [aprá:nts] 'taken' (PTCP-C.NOM.sG.)

b.

\begin{tabular}{|c|c|c|c|c|}
\hline /ep: - á:nt - ts/ & Culm & MAX(Accent) & DEP(Accent) & ALIGN-L \\
\hline a. apráints & & & & $*$ \\
\hline éprants & & $* !$ & $*$ & \\
\hline
\end{tabular}

a. /wék - á:nt - an/ $\rightarrow$ wekantan [wé:kantan] 'demanded' (PTCP-C.ACC.SG.)

b.

\begin{tabular}{|lr||c|c|c|c|}
\hline \multicolumn{2}{|c|}{ /wék - árnt - an/ } & CUlm & MAX(Accent) & DEP(Accent) & ALIGN-L \\
\hline \hline a. & wé:ká:ntan & $* !$ & & & $*$ \\
\hline b. $\quad$ wé:kantan & & $*$ & & $* !$ \\
\hline c. & wakárntan & & $*$ & & \\
\hline
\end{tabular}

The tableaux in (16b) and (17b) mirror violation profiles already seen in the data above. When there is one accented morpheme as in (16b), stress is assigned to this morpheme; and when there are multiple accented morphemes as in (17b), it is the leftmost that "wins," i.e. receives primary stress.

Finally, the constraint ranking in (10) correctly accounts for prefixed verbal forms. Prefixing is an extremely limited operation in Hittite. One of only two prefixes in the language that may be synchronically segmentable is /pé-/ ( $p e-)$, which indicates motion away from a speaker. As (18) shows, this prefix is accented, attracting stress in combination with an accented inflectional ending:

a. /pé - ta: - téni/ $\rightarrow$ pēdatteni [pé:tatieni] 'you take there' (DIR-2PL.NPST.ACT.)

b.

\begin{tabular}{|lr||c|c|c:c|}
\hline \multicolumn{2}{|c|}{$/$ pé - ta: - t:éni/ } & CULM & MAX(Accent) & DEP(Accent) & ALIGN-L \\
\hline \hline a. & pértatié:ni & $* !$ & & & $* *$ \\
\hline b. & péstat:eni & & $*$ & & $*$ \\
\hline c. & petat:é:ni & & $*$ & & $*$ ! \\
\hline
\end{tabular}


What (18) crucially demonstrates is that Hittite has a preference for leftmost stress, not root stress, which is found in other stress systems, e.g. Chukchee or Nisgha (see Alderete 2001:70). Candidates (b) and (c) in (18b) are both equally harmonic with respect to an alternative constraint (e.g. Align-L(Pk; Root)) that would require stress to fall on the first syllable of a root; however, ALIGN-L(PK, $\omega)$ properly selects $(b)$, the attested Hittite form, as the winner.

3.5. SynCHRONIC STATUS OF THE BAP? Even if empirically valid, the analysis developed in sections 3.2-3.4 might be challenged on other grounds. An alternative approach to these stress patterns might view them as purely historical "residue" - viz. lexically listed surface forms transmitted directly (modulo sound change) from a still earlier prosodic system that operated according to different principles - rather than the result of a synchronic interaction between the ranked phonological constraints in (10) and the accentual properties of morphemes. ${ }^{13}$

Without native speaker intuitions, it is of course impossible to be certain whether the proposed analysis has any cognitive reality, i.e. reflects speakers' knowledge about their language. Nevertheless, there are several good reasons to prefer it to the wholly historical account. While it is perhaps conceivable that the basic inflectional paradigms of many radical verbs are holistically stored, ${ }^{14}$ this is less plausible for imperfectives and participles, which could be formed by a Hittite speaker at any point in time to any verbal stem, each with its own idiosyncratic accentual properties. Rather, stress patterns in these productive categories are much more likely to reflect the operation of synchronic morphophonological processes.

Even more telling, though, is a subset of Hittite imperfectives that have multiple attested forms, some of which are likely to be archaic and thus potentially inherited, while others are younger, showing changes in their phonological shape driven by Hittite-internal phonotactic innovations. ${ }^{15}$ Significantly, both the older forms in (19a) and younger forms in (19b) of fixed stress roots display the exact same surface stress patterns (cf. Kimball 1999:198-9; Melchert 2013:179):

a. ānšikizzi [á:nsik:iți] 'wipes' (IPFV-3sG.NPST.ACT.)

āršikitta [á:rısik:it:a] 'washes' (IPFV-3sG.NPST.ACT.)

b. ānaškizzi [ánnsk:itsi] / ānšiškizzi [árnsiskitsi] 'wipes' (IPFV-3sG.NPST.ACT.)

ārriškizzi [árr:isk:itsi] 'Washes' (IPFV-3sG.NPST.Aст.)

Since Hittite imperfectives overwhelmingly show suffixal stress, the fixed root stress of the verbal forms in (19) makes them exceptional in their morphological category; nevertheless, when "renewed" by a subsequent generation of Hittite speakers, this exceptional stress pattern persists. The simplest explanation for this situation is that these speakers have acquired a grammar in which the features relevant to stress assignment are diachronically stable — in the case of (19), accented roots lá:ns-/ 'wipe' and /ár:-/ 'wash' and the constraint ranking in (10) which — as discussed

\footnotetext{
${ }^{13}$ Under traditional "paradigmatic" approaches to IE word stress, radical verbs exhibiting mobile stress are sometimes categorized as "hysterokinetic," a label that refers to prosodic patterns in which stress shifts between the final syllable of a word's stem and inflectional endings; see further discussion in section 4.3.

${ }^{14}$ Note that many of these are common verbs situated at the core of lexicon - e.g. 'be', 'take', 'drink', etc.; nevertheless, I view this scenario as highly unlikely.

${ }^{15}$ The phonological constraint driving epenthesis in $/-R \mathrm{~s} . /(R=$ sonorant $)$ syllabic codas is an archaic and probably inherited feature in Hittite given its affinities to the PIE ban on $/-R F . /$ ( $F=$ fricative) codas that motivates SzEMERÉNYI's LAW (Szemerényi 1970 [1989]; cf. Sandell and Byrd 2014); its demotion in the grammar appears to be an innovation of the post-OH period.
} 
in section 3.1 above - instantiates Kiparsky and Halle's (1977) BAP. This explanation in turn implies that the BAP was synchronically operative within the Hittite historical period.

4. Reconstructing PIE stress assignment: Section 3 presented a new synchronic analysis of attested Hittite stress patterns in verbal inflection, deriving these patterns via interactions between ranked phonological constraints and the accentual properties of morphemes. This section turns to comparative reconstruction: having briefly considered evidence for similar verbal stress patterns in other Anatolian languages (4.1), I assess the implications of this evidence for the PA situation, and in turn, of the PA stress system for PIE reconstruction (4.2).

4.1. Anatolian COMPaRAtive EVIDEnCE: Due to poverty of attestation and lack of secure philological diagnostics, the non-Hittite Anatolian languages offer very limited evidence for word stress in verbal inflection. ${ }^{16}$ However, a Hittite-like mobile stress pattern is observed in at least one radical verb in Palaic, muš- 'become satiated', whose attested forms would admit the same analysis, i.e. (20): ${ }^{17}$

$$
\begin{aligned}
& \text { Pal. /mus - si/ } \rightarrow \text { mūši [mússi] 'you become satiated' (2sg.npst.Act.) } \\
& \text { /mus - ánti/ } \rightarrow \text { mušānti [musá:nti] 'become satiated' (3рL.nрsт.Аст.) }
\end{aligned}
$$

Moreover, Palaic cognates of Hittite mobile mi-verbs also appear to consistently show the same surface stress, e.g. (21):
a. Pal. $\bar{a} \check{s} d u$ [áss-tru] 'let him be' (3s.ImP.Act.)
b. Pal. ahuwānti [a $\chi^{\mathrm{w}}$-á:nti] 'drink' (3PL.nPST.Aст.)
c. Pal. atānti [at-á:nti] 'eat' (3PL.nPst.Aст.)

(cf. Hitt. ē $\check{S} d u$ [éss-tru])

(cf. Hitt. akuanzi [ak ${ }^{\mathrm{w}}$-ántsi] $)$

(cf. Hitt. adanzi [at-ántsi)

Such evidence, albeit limited, is at least consistent with the hypothesis that Palaic and Hittite stress assignment are fundamentally identical, with both languages sharing the constraint ranking in (10).

Perhaps more significantly, the general phonological preference for left-edge stress (i.e. ALIGNL) has been implicated in a pattern of diachronic prosodic change in which words reconstructed for PIE with word-internal stress tend to surface in Anatolian (and the other IE languages) with unmarked leftmost stress (Yates 2015a). ${ }^{18}$ Here it is sufficient to note that the diachronic effects of this constraint extend beyond Hittite, motivating the innovative leftmost stress of, e.g., (22):

$$
\begin{array}{ll}
\text { Pal. šūna-t } \text { [sú:nat] 'filled' (3s.Psт.Аст.) } & <\mathrm{PIE} * s u-n e ́-h_{3}-t \\
\text { CLuw. tarri-* [tá:r:i-] 'three'19 } & <\mathrm{PIE} * \text { trí- }
\end{array}
$$

Synchronic and diachronic evidence from the other Anatolian languages thus aligns with Hittite with respect to the BAP, supporting its reconstruction for their common ancestor, Proto-Anatolian.

\footnotetext{
${ }^{16}$ The lack of evidence in Cuneiform Luwian for mobile stress in verbal inflection is somewhat surprising. Given that Luw. /a/ appears to lengthen under stress in both open and closed syllables (Melchert 1994:247), one might expect to find at least a few examples of plene writing in the (relatively) robustly attested 3rd plural of radical verbs, yet this is unattested.

${ }^{17}$ As in Hittite, plene writing is the principal orthographic diagnostic of stress in Palaic (cf. 2.2 above).

${ }^{18}$ Analogous explanations have been proposed for very similar diachronic stress "retraction" phenomena observed in Vedic Sanskrit (Lundquist 2015; cf. Sandell 2015) and in Ancient Greek (Probert 2006).

${ }^{19}$ Attested only indirectly in CLuw. tarriyannalli- 'third-in-command'.
} 
4.2. ReCOnstructing PIE StRess: The implications of Anatolian for PIE stress assignment are clear: the evidence converges with Kiparsky and Halle's (1977) reconstruction of the BAP for PNIE, thereby strongly arguing that this principle — or equivalently, the phonological constraint ranking in (23) - was also operative in PIE itself:

$$
\begin{aligned}
& \text { PIE StRess ASSignMENT: } \\
& \text { Culminativity } \gg \operatorname{MAX}(\text { Accent }) \gg \operatorname{DeP}(\operatorname{Accent}), \operatorname{Align}-\mathrm{L}(\mathrm{Pk}, \omega)
\end{aligned}
$$

Anatolian also provides important evidence for morphological reconstruction - specifically, for reconstructing the lexically specified accentual properties of the roots and affixes that serve as the inputs to (23). For instance, it was shown in 3.2 that Hittite has a synchronically unaccented root /ses-/ 'sleep', which combines with inflectional endings that are unaccented in the singular (e.g. 3SG /-tsi/), and accented in the plural (3PL /-ántsi/. Synchronic, system-internal diagnostics in Vedic Sanskrit show that the same is true for the cognate root (/sas-/) and endings (/-ti/, /ánti/). Agreement between Hittite and Vedic argues that morphemes with these properties should be reconstructed for PIE, i.e. */ses-/ 'sleep', */-ti/ (3SG), */-énti/ (3PL).

Provided with these inputs, the constraint ranking in (23) yields the PIE paradigm in (24), which develops into the attested Hittite and Vedic surface forms by regular sound change:

$$
\begin{aligned}
& \text { a. } \quad * / s e s-\text { ti/ } \rightarrow * \text { [sésti] 'sleeps' (3sG.pRs.Act.) }>\text { Hitt. šěšzi [séstşi], Ved. sásti } \\
& \text { b. */ses - énti/ } \rightarrow * \text { [sasénti] 'they sleep' (3PL.prs.Act.) }>\text { Hitt. šašanzi [sasántsii], } \\
& \text { c. }
\end{aligned}
$$

\begin{tabular}{|lr||c|c|c:c|}
\hline \multicolumn{2}{|c|}{$*$ ses - énti/ } & CULM & MAX(Accent) & DEP(Accent) & ALIGN-L \\
\hline \hline a. & *sesenti & $* !$ & $*$ & & \\
\hline b. & *sasénti & & & & $*$ \\
\hline c. & *sésenti & & $* !$ & $*$ & \\
\hline
\end{tabular}

It is a positive result and a useful check on the method that standard IE handbooks reconstruct PIE paradigms of exactly this kind (e.g. Fortson 2010:96). The novel feature of the analysis developed here is that it not just describes but predicts this pattern, and offers a principled explanation (i.e. root accentedness) for radical verbs that synchronically deviate from it in their basic inflectional paradigm as well as in inflectionally related verbal categories.

4.3. ImPlicATIONS OF THE RECONSTRUCTION: The analysis developed here is further recommended by two of its broader implications for the PIE morphological system. First, the reconstruction of (23) imposes clear constraints on possible synchronic stress patterns in PIE inflectional paradigms, including in the nominal system: in short, inflectional mobility must be BAPcompliant. Yet unlike in (24), where it converges with long-established reconstructions, this prediction has the effect of ruling out certain patterns of stress mobility reconstructed under traditional analyses of IE nominal stress - in particular, the intraparadigmatic stress alternation between root and derivational suffix characteristic of "proterokinetic" nouns, one of the four templatic classes posited under the widely accepted "Erlangen model" of IE nominal morphophonology. ${ }^{20}$ Yet given

${ }^{20}$ These "paradigmatic" classes assume a morphological template $\mathrm{R}(\mathrm{oot})+($ derivational) $\mathrm{S}(\mathrm{uffix})+$ (inflectional) E(nding). For an overview of these classes, see (e.g.) Fortson (2010:119-22) and Weiss (2011:257-61). Both 
the lack of compelling evidence for synchronic stress mobility of this kind in any of the ancient IE languages, ${ }^{21}$ the failure of (23) to generate this pattern in fact seems to be a virtue of the analysis, which thereby serves to confirm that - to the extent that such a nominal paradigm is reconstructible at all — it must be situated in Pre-PIE, just as Schindler (1975) had originally argued (cf. Hale 2010). More generally, the reconstruction of (23) for PIE suggests that these traditional labels have as little explanatory power for PIE stress as they do for its oldest daughter languages, where the surface distribution of word stress is demonstrably a more complex function of the accentual properties of morphemes and language-specific phonological principles (cf. Kiparsky 2010:176).

A second advantage of this analysis is that it allows for a more constrained account of diachronic prosodic change, directly linking innovations in surface stress to innovations in the morphological component (i.e. changes in the accentual properties of roots or affixes) or in the ranking of phonological constraints (cf. Kiparsky 2015:82-3). For instance, the emergence of fixed left-edge stress in Germanic, Italic, and Celtic can be explained by the (eventual) promotion of ALIGN-L(Pk, $\omega)$ over MAX(Accent), with consequent loss of all lexical accentual features (cf. Halle 1997:298-9). ${ }^{22}$ While the details of such a development remain to be worked out more fully (see Yates (2015a:178-80) for discussion), this explicit formulation of the change may provide a useful starting point for future investigation. The reconstruction of (23) for PIE therefore establishes a secure foundation for developing a holistic picture of PIE word stress (and more generally, PIE morphophonology), as well as for analyzing subsequent prosodic change in the daughter languages.

\section{References}

Alderete, John D. 2001. Morphologically Governed Accent in Optimality Theory. New York: Routledge.

Fortson, Benjamin W. 2010. Indo-European Language and Culture, 2 edn. Oxford, U.K. / Malden, MA: Wiley-Blackwell.

Hale, Mark. 2010. Návyasā vácah: To Praise with a Really Old Word. In Ronald Kim, Norbert Oettinger, Elizabeth Rieken and Michael Weiss (eds.), Ex Anatolia Lux: Anatolian and IndoEuropean Studies in honor of H. Craig Melchert on the Occasion of his Sixty-Fifth Birthday, 85-97. Ann Arbor, MI / New York: Beech Stave Press.

Halle, Morris. 1997. On Stress and Accent in Indo-European. Language 73.275-313.

Hoffner, Harry A., and H. Craig Melchert. 2008. A Grammar of the Hittite Language. Vol. I: Reference Grammar. Winona Lake, IN: Eisenbrauns.

Hrozný, Friedrich. 1917. Die Sprache der Hethiter. Leipzig: J.C. Hinrichs.

are representative of the prevailing trend in IE studies to ascribe these classes — including proterokinetic - to PIE itself. A still more extreme view is that of Kloekhorst (2013:38-9), who situates the Erlangen classes in "late" PIE.

${ }^{21}$ See generally Kiparsky (2010) and Kümmel (2014); moreover, Lundquist (2015) has now convincingly refuted the idea that Vedic $t i$-stem nouns were mobile at any shallow prehistoric stage.

${ }^{22}$ Assuming such re-ranking, the loss of lexical accents would fall out straightforwardly from lexicon optimization (Prince and Smolensky 1993/2004:209-14). 
Hyman, Larry. 2006. Word prosodic typology. Phonology 2.225-257.

Kavitskaya, Darya. 2001. Hittite Vowel Epenthesis and the Sonority Hierarchy. Diachronica 18(2).267-299.

Kimball, Sara. 1999. Hittite Historical Phonology. Innsbruck: Institut für Sprachwissenschaft der Universität Innsbruck. 2015. Review Article: A. Kloekhorst (2014), Accent in Hittite. Kratylos 60.18-42.

Kiparsky, Paul. 2010. Compositional vs. Paradigmatic Approaches to Accent and Ablaut. In Stephanie W. Jamison, H. Craig Melchert and Brent Vine (eds.), Proceedings of the 21st Annual UCLA Indo-European Conference, Los Angeles, October 30-31, 2009, 137-181. Bremen: Hempen.

- 2015. New Perspectives in Historical Linguistics. In Claire Bowern and Bethwyn Evans (eds.), The Routledge Handbook of Historical Linguistics, 64-102. London / New York: Routledge.

Kiparsky, Paul, and Morris Halle. 1977. Towards a Reconstruction of the Indo-European Accent. In Larry Hyman (ed.), Studies in Stress and Accent, 209-238. Los Angeles: University of Southern California Press.

Kloekhorst, Alwin. 2008. Etymological Dictionary of the Hittite Inherited Lexicon. Leiden / Boston: Brill.

. 2013. Indo-European nominal ablaut patterns: The Anatolian evidence. In Götz Keydana, Paul Widmer and Thomas Olander (eds.), Indo-European Accent and Ablaut, 107-28. Copenhagen: Museum Tusculanum Press.

- 2014. Accent in Hittite: A Study in Plene Spelling, Consonant Gradation, Clitics, and Metrics. Wiesbaden: Harrassowitz.

Kümmel, Martin. 2014. Zum "proterokinetischen" Ablaut. In Norbert Oettinger and Thomas Steer (eds.), Das indogermanische Nomen: Akten der Arbeitstagung der Indogermanischen Gesellschaft, Erlangen, 2011, 164-179. Wiesbaden: Reichert.

Lundquist, Jesse. 2015. On the Accentuation of Vedic -ti- Abstracts: Evidence for Accentual Change. Indo-European Linguistics 3.42-72.

Melchert, H. Craig. 1994. Anatolian Historical Phonology. Amsterdam / Atlanta: Rodopi.

_. 2013. Hittite "Heteroclite" s-Stems. In Adam I. Cooper, Jeremy Rau and Michael Weiss (eds.), Multi Nominis Grammaticus: Studies in Classical and Indo-European linguistics in honor of Alan J. Nussbaum on the occasion of his sixty-fifth birthday, 175-184. Ann Arbor / New York: Beech Stave Press.

—. 2014. "Narten formations" versus "Narten roots". Indogermanische Forschungen $119.251-258$. 
- to appear. The Position of Anatolian. In Andrew Garrett and Michael Weiss (eds.), Handbook of Indo-European Studies. Oxford / New York: Oxford University Press.

Prince, Alan, and Paul Smolensky. 1993/2004. Optimality Theory: Constraint Interaction in Generative Grammar. Oxford / Malden, MA: Blackwell.

Probert, Philomen. 2006. Ancient Greek Accentuation: Synchronic Patterns, Frequency Effects, and Prehistory. Oxford / New York: Oxford University Press.

Revithiadou, Anthoula. 1999. Headmost Accent Wins: Head Dominance and Ideal Prosodic Form in Lexical Accent Systems. Ph.D. diss., Leiden University.

Sandell, Ryan. 2015. Productivity in Historical Linguistics: Computational Studies in Word Formation in Ancient Greek and Sanskrit. Ph.D. diss., University of Californa, Los Angeles.

Sandell, Ryan, and Andrew M. Byrd. 2014. In Defense of Szemerényi's Law. Paper presented at the 33rd Annual East Coast Indo-European Conference, Blacksburg, VA, 5-7 June 2014.

Schindler, Jochem. 1975. Zum Ablaut der neutralen $s$-Stämme des Indogermanischen. In Helmut Rix (ed.), Flexion und Wortbildung: Akten der V. Fachtagung der Indogermanischen Gesellschaft, Regensburg, 9. bis. 14. September 1975. Wiesbaden: Reichert.

Sturtevant, Edgar H. 1929. The relationship of Hittite to Indo-European. Transactions and Proceedings of the American Philological Association 60.25-37.

—. 1933. Archaism in Hittite. Language 9.1-11.

Szemerényi, Oswald. 1970 [1989]. Einführung in die vergleichende Sprachwissenschaft. Darmstadt: Wissenschaftliche Buchgesellschaft.

Weiss, Michael. 2011. Outline of the Historical and Comparative Grammar of Latin. Ann Arbor / New York: Beech Stave Press.

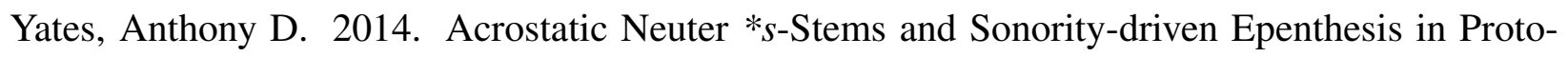
Anatolian. Paper presented at the 33rd Annual East Coast Indo-European Conference, Blacksburg, VA, 6-8 June 2014.

—. 2015a. Anatolian Default Accentuation and its Diachronic Consequences. Indo-European Linguistics 3.145-187.

2015b. On the relationship between stress and vowel quantity in Hittite. Paper presented at the 27th Annual UCLA Indo-European Conference, Los Angeles, 23-24 October 2015. 